\title{
Uncertainty of the implementation time of geodynamic monitoring system in multi-criteria ranking of alternatives
}

\author{
O.R. Kuzichkin ${ }^{1}$, I.V. Loginov $^{2}$, V.T. Eremenko ${ }^{3}$, S. V. Eremenko ${ }^{4}$, G.S.Vasilyev ${ }^{5}$, \\ A.V. Grecheneva ${ }^{6}$ \\ 1,5,6 Belgorod State University, Russia \\ ${ }^{2,3,4}$ Orel State University, Russia
}

\section{Article Info}

Article history:

Received Jun 28, 2019

Revised Sep 25, 2019

Accepted Oct 9, 2019

\section{Keywords:}

Geodynamic monitoring system

Implementation time

Incompleteness

Ranking

Requirements change

Requirements system

Corresponding Author:

O.R. Kuzichkin,

Belgorod State University, 85 Pobedy St, Belgorod, Russia.

Email: ijeecs.iaes@gmail.com

\begin{abstract}
The paper deals with the problem of ranking alternatives to geodynamic monitoring systems in the case of uncertainty of their implementation time. The problem is characterized by the fact that the choice of alternatives and the effect of it depends on the quality properties of the applied organizational and technical solutions, taking into account the time of implementation. The ordering of alternatives is proposed taking into account the uncertainty of the implementation time factors. Ranking is realized by comparing the trees of functional characteristics of alternatives taking into account the compliance of their characteristics with time-varying requirements. The scope of the proposed method is the choice of configurations of geodynamic monitoring systems with significant differences in the implementation time of alternatives.
\end{abstract}

Copyright () 2020 Institute of Advanced Engineering and Science. All rights reserved.

\section{INTRODUCTION}

Factors of change of functional characteristics of geodynamic monitoring systems due to their modernization and requirements to technical means, embedded in reconfigurable technological processes, cause the need to take into account the time factor when comparing alternatives. There is a decrease in the duration of active use in the life cycle processes of monitoring systems. On the other hand, when deploying complex geodynamic monitoring systems, the risks of successful observations are high, which generally leads to significant uncertainty in the implementation time of systems with established requirements. At the same time, there is a natural process of changing the requirements themselves. For example, the requirements for the organization of geodynamic monitoring of life-supporting high-risk objects (such as nuclear power plants) for a period of 10 or 20 years will vary significantly, which determines different suitability of the options under consideration. Well-known apparatus of multi-criteria ranking of alternatives involves taking into account the time factor in one of the particular indicators, which generally limits the adequacy of the ranking decisions. This situation determines relevance of the development of the multi-criteria ranking method, taking into account the additional uncertainty of the implementation time of geodynamic monitoring systems.

\section{OVERVIEW OF KNOWN APPROACHES TO UNCERTAINTY-TIME IMPLEMENTATION OF COMPLEX SYSTEMS}

Changing the characteristics of monitoring systems over time due to modernization processes leads to modification of the task of ranking alternatives to the form, taking into account the uncertain nature of the 
time factor of systems implementation and deployment. This situation determines need to refine the ranking apparatus of alternatives to the considered technical solutions for the modernization of technological processes. This is typical for all existing classes of ranking methods: on the basis of weight coefficients, solving matrices with step-by-step estimates and information approach [1-2].

For fast-growing sectors of the economy, there is a change in the systems of requirements for indicators of ranked systems, ranges of their values [3-7]. Dynamic change of preferences is considered to take into account the uncertainty factor of time changes of requirements systems [8, 9]. To account for changes in requirements, approaches are used both on the basis of decision-making theory (analysis of the preferences dynamics, for example, cardinal utility theory), and on the basis of forecasting the values of requirements.

Accounting for changes in preferences of decision maker (system requirements) is used in the theory of decision-making. For example, in [10, 11]decision-making problems in the conditions of dynamic change of alternatives value are considered. In [12] the problems of discounting and time preferences between alternatives, including the model of discounted integral effect are considered. The approach of net discounting is used as the difference between the cost of resources and net income from the results of the implementation of a complex system [8]. The solution of the problem of choosing alternatives taking into account the factor of changing the preference of subjects in time using the temporal approach takes into account the possibility not only of changing the value of the alternative, but the dynamic nature of decision-making [13].

Hyperbolic, quasi-hyperbolic, exponential, linear and power functions of discounting [13-15] showing the change of system requirements, are used to solve the problems of time factor accounting. Information is used not only about the uncertainty of the factors values, but also the change in the amount of uncertainty depending on the conditions of decision-making under risk [9]. The use of such functions is possible in the conditions of non-stationary behavior of the decision maker and shows that the evaluation of utility depends on the time and conditions of choice of alternatives.

The use of criterion functions, changed in time, is widespread in solving the problems of choice and ordering of alternatives. In [16] application of fuzzy temporal utility for search of necessary information in databases is considered. In [17] use of utility functions for scheduling in distributed computing on the basis of the most useful plans of computing was substantiated. In [18] justification problems of a probabilistic dynamic method of a consumer choice and determination of usefulness of the goods forming optimum consumer behavior of the subject are considered.

Accounting for the time of implementation (modernization) of an alternative to a complex system is used in solving the problems of development programs. The simplest way of planning is to develop a project portfolio plan with one time limit, taking into account its uncertainty [19]. More complex models, for example, as in [20], assume three types of resources in the development of programs: labor, financial and material. In general, multi-criteria ranking methods are used. Risk factors are additionally taken into account [21].

Known methods [22], used to rank the alternatives of complex system requirements are divided into linear and nonlinear weight models; categorical models; weighted point models; models of total cost of ownership; adapted models, built using the methods of neural networks and the main component; models of the theory of multidimensional utility. The fuzziness of many factors determines the application of a fuzzy management model, in particular, to align the value-oriented portfolio of projects [23]. Analysis method of hierarchies and its additions focused on the account of data and criteria fuzziness (Voting Analytical Hierarchy Process (AHP), Fuzzy extended AHP) has found a significant distribution [22, 24-27]. For example, in [28] an approach to the evaluation of efficiency and effectiveness of it processes based on a hybrid five-layer neuro-fuzzy ANFIS system, built on functionally equivalent Sugeno systems is proposed. Ranking of variants of complex systems by such methods allows uncertainty of initial estimates of alternatives, in general, should be supplemented by taking into account the time factor. Ranking problems under conditions of a set of contradictory criteria [29], the solution of which is achieved by successive dimension reduction of the characteristic space by means of verbal analysis of solutions and/or their combinations, are considered. A more common situation is the case of several decision centers with different preferences [30].

Methods for ranking complex systems, such as it services [31-33], are based on multiparameter models of functional states that aggregate the characteristics of implementation and use of components. The following system models are distinguished: consumer-oriented [34], information and automation oriented systems [35], context-dependent models [36], template representation models [37]. The majority of research focuses on 15-25 partial indicators used for evaluation. In some evaluation tasks, the number of indicators can reach several hundred, for example, when choosing a platform for automation [17]. The calculation of their values is based on multilevel hierarchies. For example, in [27] six levels of hierarchy 
of such model are allocated: two macro indicators at the level of strategic estimates - resources and quality which at the level of criteria are developed into capital and operational costs, technical and operational quality, and also quality of the supplier.

The construction of a dynamic requirements system shows the need to manage requirements in the implementation of development programs, for example, in [38] a three-stage model - the choice of business requirements, the construction of a model taking into account additional constraints and the formulation of system requirements in the construction of work plans.

The results of the analysis of time factors used in the methods of multi-criteria ranking of alternatives in the conditions of fuzzy initial data show that multiparameter models are used, taking into account the technical, system and organizational and legal parameters of geodynamic monitoring systems, considering their fuzziness and risk. Systems of requirements for them have a complex structured form and do not fully take into account the change in requirements for individual properties. This substantiates the relevance of the apparatus development of multi-criteria ranking monitoring systems when changing the beneficial effect of the use of systems in time.

\section{THE PROBLEM OF MONITORING SYSTEMS RANKING UNDER UNCERTAINTY OF IMPLEMENTATION TIME}

Solution of the problem of the uncertainty factor influence of the characteristics of monitoring systems alternatives, taking into account time factors, is considered while modernizing given technological process of geodynamic observations organization. For such technological process the bottleneck (problem) is revealed, the decision and effect on it depends on the applied organizational and technical decisions taking into account time of modernization. In this case, the preference for alternatives is determined taking into account the uncertainty of time factors. Therefore, the task of ranking alternatives is complicated by the uncertainty of the introduction time of new technical solutions.

Mathematical formulation of the problem has the following form:

Known:

a. many alternatives to monitoring systems $A=\left\{A_{i}\right\}, i=(1, I)$ that can be used to solve the problem of improving the technological process.

b. the system of requirements $Q S$ set to the class of monitoring systems. Requirements system $Q S$ is the complex criteria tree $K=\left\{k_{j}\right\}$ over the set of individual criteria $k_{i}$ to individual functional elements $f s_{i}: \overline{Q S}=\left\langle K \cup\left\{k_{i}\right\}, E\right\rangle$, where $E=\left(K \cup\left\{k_{i}\right\}\right) \times\left\{k_{i}\right\}$.

c. each particular criterion is a function $k_{i}$ of the functional indicator $f_{s}: k=\langle D(f s)$; $\Psi\rangle$, where $D\left(f_{s}\right)-$ the area of permissible values of the $f_{s}$ indicator; $\Psi=\Psi(t)$ - criterion for assessing the quality of the indicator - the value of the criterion changes over time.

d. a model for describing the functional characteristics of the monitoring system alternatives in the form of a functionality tree template $\overline{F S}$. The alternative model is a hierarchy of functional indicators of a multicomponent system $\overline{F S} \rightarrow F S, F S=\langle F \cup\{f s\}, K F\rangle$, where $f s$ is characterizing primary indicator, $f_{s}=f_{s}(t)$ are values of the indicator changing over time; $\left\{f_{s}\right\}$ is a set of characterizing indicators; $F$ : $f_{i} \in F: f_{i}=\Omega_{i}(\{f s\})$ is a set of complex indicators; $K F: K F \subseteq(F \cup\{f s\}) \times F$ is the ratio of aggregation between indicators. As part of the system of indicators $\left\{f_{s}\right\}$ there is an indicator $f_{s}{ }^{\langle\tau\rangle}$ characterizing implementation time of alternatives for the technological process.

e. planned use time of the technological process, for the modernization of which the alternative $T$ is intended.

Find: ranking $R=\left\{r_{i}\right\}$ of alternatives $a_{i} \in A$ on a set of complex criteria $K \in Q S$ of the requirements system, taking into account the uncertainty of the implementation time $f_{s}{ }^{\langle\tau\rangle}$.

\section{METHOD OF MONITORING SYSTEMS RANKING UNDER UNCERTAINTY OF IMPLEMENTATION TIME}

To take into account the uncertainty factor of the implementation time of the geodynamic monitoring system when ranking alternatives, it is proposed to modify the partial criteria to consider the cumulative effect on the planning period. The essence of the proposed ranking method is as follows: 
a. Computation of conditional values of the functional parameters $f_{s}(t)$ given the implementation time uncertainty of an alternative $f_{s}^{\langle\tau\rangle}$, given a probability distribution function of the time points $\varphi_{i}(t)$ as shown in Figure 1:

$$
f \tilde{s}_{i j}(t)=f s_{i j}(t) \varphi_{i}(t)
$$
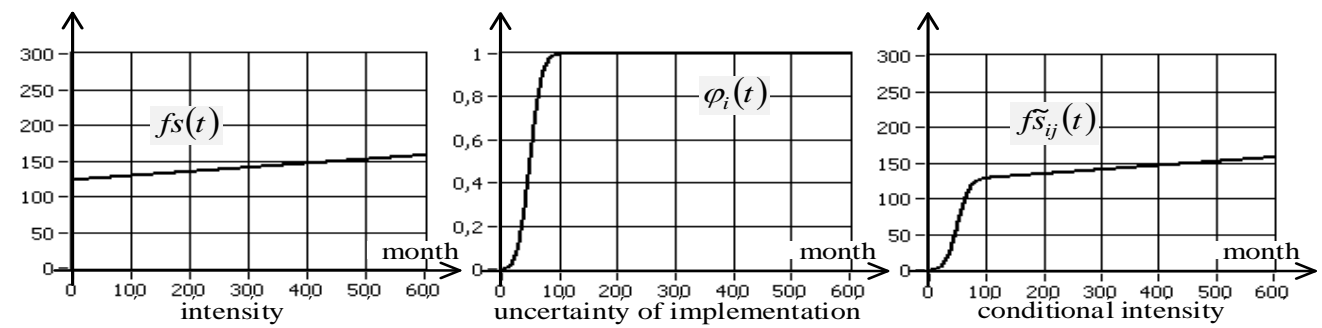

Figure 1. Calculation example of conditional values of functional indicators considering time uncertainty of alternative implementation

b. Calculation of the quality indicator ${ }^{q s_{i j}}(t)$ for all alternatives for each particular indicator $f \tilde{s}_{i j}(t)$, taking into account the dynamics evaluation criterion $\Psi=\Psi(t)$ :

$$
q s_{i j}(t)=\Psi\left(f \tilde{s}_{i j}, t\right)
$$

Remark: Figure 2 shows an example with three options for changing the performance criterion: he first and second options determine a significant and moderate increase in the performance requirements, and the third option shows a decrease in the performance requirements of the technological process.
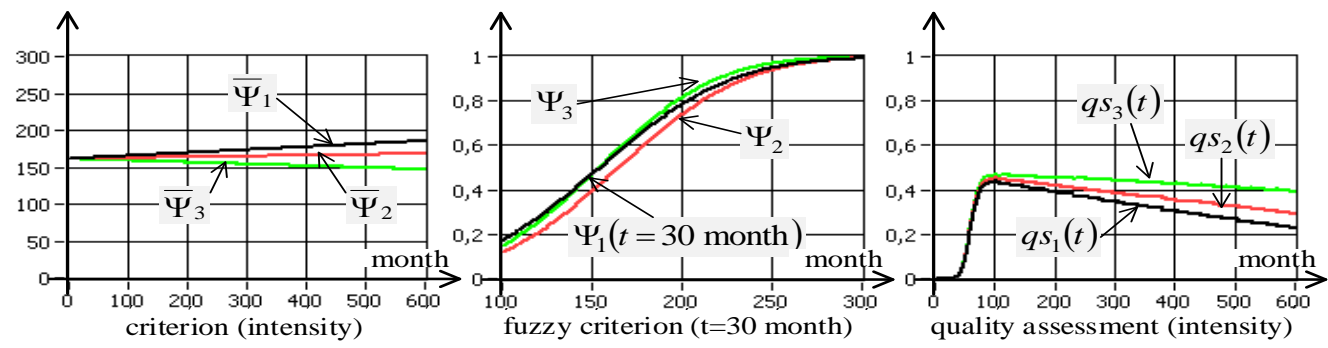

Figure 2. Calculation example of the quality indicator value considering time uncertainty of alternative implementation

c. Calculation of the average quality index ${ }^{q \hat{s}_{i j}}$ for all alternatives on the basis of changes in the value of the particular quality index $q s_{i j}(t)$ :

$$
q \hat{s}_{i j}=\int_{0}^{T} q s_{i j} d t / T
$$

d. Calculation of the convolution tree $\Phi^{+}$by determining the edges weights $\phi_{i j}=g\left(e_{\left(w_{i}\right)\left(q s_{j}\right)}\right)$, reflecting importance of the complex criteria of the requirements system:

$$
\Phi \stackrel{\overline{Q S}^{+}}{\longrightarrow} \Phi^{+}
$$


In the convolution tree $\Phi$, it is proposed to use an additive convolution, implemented on the normalized features of the distances between the alternative and the ideal object:

$$
\Phi=\sum_{i=1}^{n} \phi_{i} k_{i}, k_{i} \in[0 ; 1]
$$

where $\sum_{i=1}^{n} \phi_{i}=1 ; n$ is a number of subsidiary criteria.

If $\sum_{i=1}^{n} \phi_{i}>1$, then the normalization step function is being used:

$$
\Phi=\left\{\begin{array}{c}
\phi_{0 k}+\sum_{i} \phi_{i} q s_{i}^{\Delta} /(k+1) ; \Phi_{k}<\sum_{i} \phi_{i} q s_{i}^{\Delta} \leq \Phi_{k+1} \\
\sum_{i} \phi_{i} q s_{i}^{\Delta} ; \sum_{i} \phi_{i} q s_{i}^{\Delta} \leq \Phi_{k}
\end{array}\right.
$$

A variant of the convolution tree for the alternatives to information and telecommunication systems is shown in Figure 3.

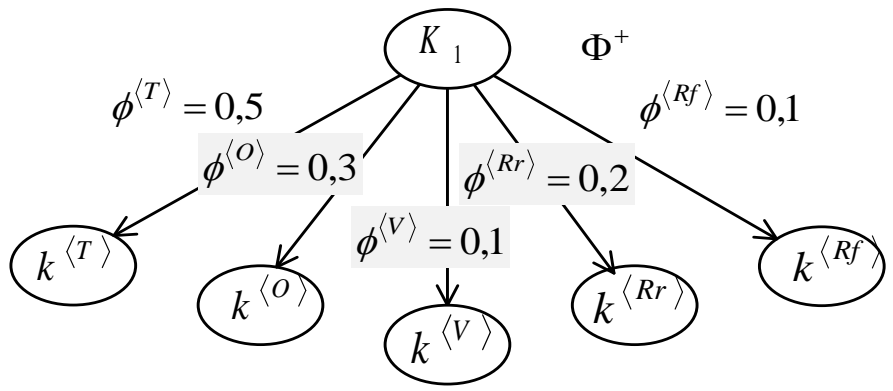

Figure 3. $\Phi^{+}$convolution tree

e. Calculation of an ideal option $A^{*} \Rightarrow F S^{*}$ based on the requirements system and the values of the functional parameters of the alternatives:

$$
\left\{A_{i}\right\}, \overline{Q S}^{+} \rightarrow F S^{*}
$$

Private criteria values of the ideal system alternative $F S^{*}$ are calculated on the basis of the best indicators according to known estimates, taking into account the established standard requirements:

$$
f s^{*}=\left\{\begin{array}{c}
\max D(\overline{f s}), \overline{f s} \neq 0 \\
\max \left\{f s_{i}\right\}, \overline{f s}=0
\end{array}\right.
$$

f. Calculation of trees distances $\left\{Q S_{i}^{\Delta}\right\}$ from the ideal alternative is carried out for each indicator (tree leaf):

$$
q s_{i}^{\Delta}=\phi\left(q s^{*}, q s_{i}\right)
$$

g. Distance $\triangle Q S_{i}$ calculation for each alternative $A_{i}$ is realized by the convolution tree $\Phi^{+}$: 


$$
\Delta Q S_{i}=\sum_{i=1}^{n} \phi_{i} q s_{i}^{\Delta}
$$

h. Alternatives ordering according to the distance values:

$$
\Delta Q S_{i}>\Delta Q S_{j} \Leftrightarrow A_{i} \prec A_{j}
$$

\section{CONSIDERING THE UNCERTAINTY FACTOR OF IMPLEMENTATION TIME FOR INFORMATION AND COMMUNICATION SYSTEMS OF GEODYNAMIC MONITORING}

We consider application of the proposed method to the solution of alternatives selection problem while preparing development programs of information and communication environment in the process of geodynamic monitoring organization. Let set infocommunication environment in which it is necessary to reconfigure the processes associated with the increase in computing power. To solve this problem, we consider three alternatives to computing systems that implement computing power: $A=\left\{A_{i}\right\}, i=1 . .3$. Alternatives $\left\{A_{i}\right\}$ are characterized by different implementation times. It is necessary to rank the alternatives of computing systems $\left\{A_{i}\right\}$ according to the degree of suitability for use to solve the problems of information modernization of the observational network of the geodynamic monitoring system. The planned lifetime of the computer system: $T=5$ years.

Initial set of complex criteria $K \in Q S$ of the requirements system for optimization of the computational core of the geodynamic monitoring system is performed in accordance with [17]: $\left\{k_{i}\right\}=\left\{k_{1}, k_{2}, k_{3}\right\}$ as shown in Table 1 and Figure 3.

\begin{tabular}{|c|c|c|c|}
\hline Criterion & $\begin{array}{l}\text { Performance (computing power), } \\
\text { TFlops }\end{array}$ & $\begin{array}{c}\text { Usability, } 10000 / \text { person- } \\
\text { hour/year }\end{array}$ & $\begin{array}{c}\text { Full implementation cost, } 1000 \\
\text { /million rubles }\end{array}$ \\
\hline Functional criterion, $f S$ & $f s^{\langle T\rangle}$ & $f_{S}\langle O\rangle$ & $f s^{\langle R r\rangle}$ \\
\hline Criterion, $\Psi$ & Not less than 200 & Not less than 150 & Not less than 300 \\
\hline Weight, $\phi$ & 0,5 & 0,3 & 0,2 \\
\hline Criterion dynamics, $\Delta \Psi$ & $10 \%$ & $6 \%$ & 0 \\
\hline
\end{tabular}

Table 1. Characteristics of the Criteria System $Q S$
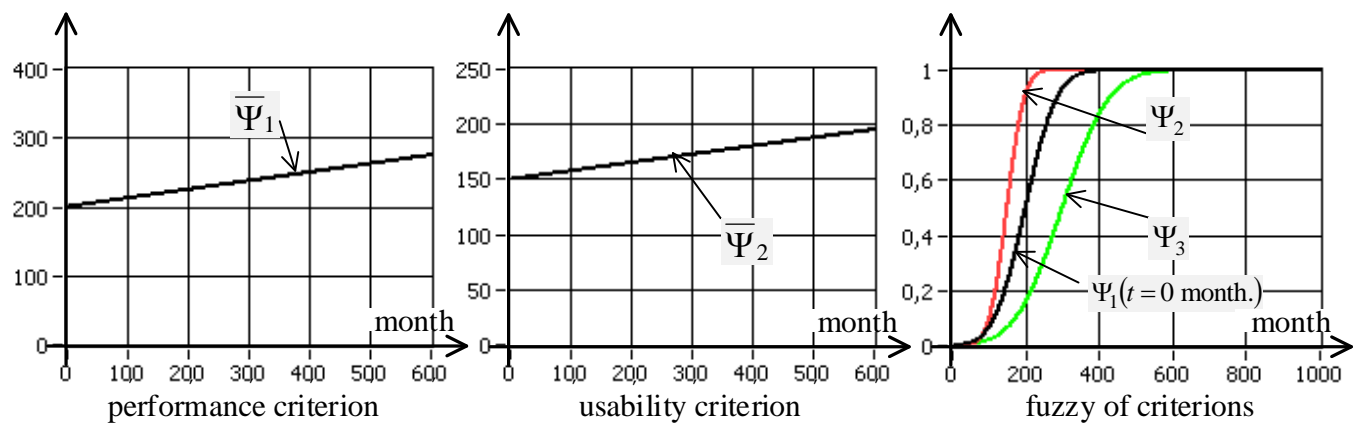

Figure 3. Values of the criteria system

Criteria values $F_{i}^{+}$for the considered alternatives of the computing system are presented in Table 2. In accordance with step 1, conditional values of functional indicators are calculated considering time uncertainty of alternative implementation $f_{s}^{\langle\tau\rangle}$. The results are shown in Figure 4. 
Table 2. Advanced Functionality Trees ${ }^{F S_{i}}$ of the System of Alternatives $\left\{A_{i}\right\}$

\begin{tabular}{|c|c|c|c|c|c|}
\hline$A_{i}$ & Criterion & $\begin{array}{c}\text { Performance (computing } \\
\text { power), TFlops }\end{array}$ & $\begin{array}{l}\text { Usability, } 10000 \\
\text { /person-hour/year }\end{array}$ & $\begin{array}{l}\text { Full implementation cost, } 1000 \\
\text { /million rubles }\end{array}$ & $\begin{array}{c}\text { Implementation } \\
\text { time, months }\end{array}$ \\
\hline$f s$ & & $f s^{\langle T\rangle}$ & $f s^{\langle O\rangle}$ & $f S^{\langle R r\rangle}$ & $f s^{\langle\tau\rangle}$ \\
\hline$\Delta$ & Value & 240 & 320 & 280 & 5 \\
\hline$A_{1}$ & Change & 5 & 3 & 4 & 3 \\
\hline$A$ & Value & 170 & 150 & 200 & 7 \\
\hline$A_{2}$ & Change & 3 & 6 & 2 & 4 \\
\hline$A_{3}$ & Value & 350 & 310 & 250 & 6 \\
\hline
\end{tabular}
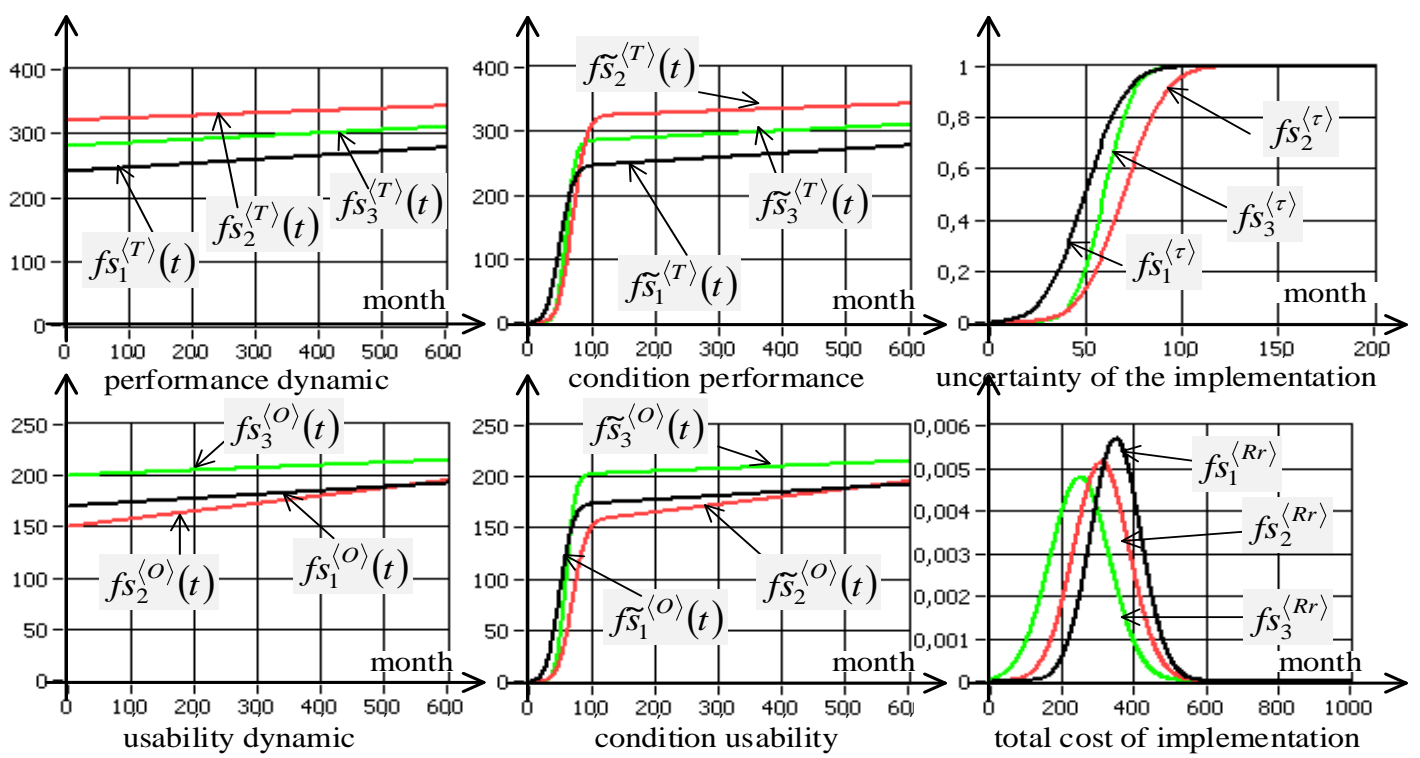

Figure 4. Criteria values according to the functionality tree of the alternatives system $\left\{A_{i}\right\}$

Calculation the quality indicator value ${ }^{q s_{i j}}(t)$ for all alternatives by each particular criterion $f \tilde{s}_{i j}(t)$ is done in accordance with step 2. The result is shown in Figure 5.
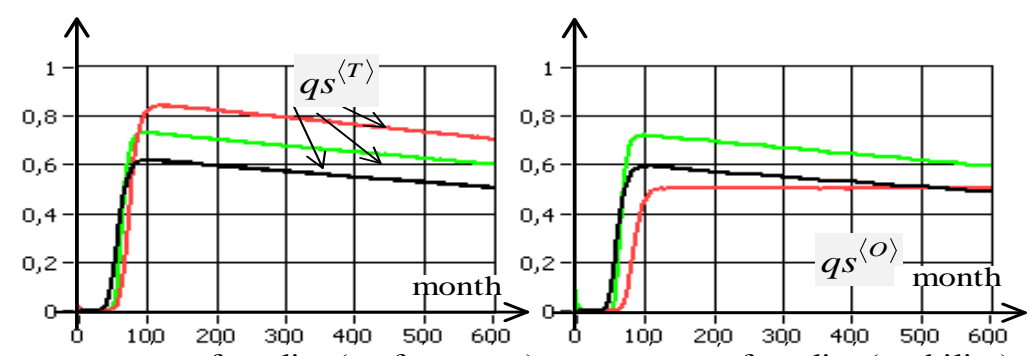

assessment of quality (performance) assessment of quality (usability)

Figure 5. Values of particular quality criteria $q s_{i j}(t)$

Calculation of the average quality criterion $q \hat{s}_{i j}$ is done in accordance with step 3. Quality criteria values for each particular criterion are calculated. According to step 4, the convolution tree is refined. In accordance with step 5 , criteria of the ideal alternative to the monitoring system $A^{*}$ are calculated. The calculation results are presented in Table 3. 


\begin{tabular}{cccc}
\multicolumn{4}{c}{ Table 3. Estimated Values of the Alternative Quality Criteria $\left\{A_{i}\right\}$} \\
\hline$A_{i}$ & Performance (computing power) & Usability & Full implementation cost \\
\hline$s$ & $q s^{\langle T\rangle}$ & $q s^{\langle O\rangle}$ & $q s^{\langle R r\rangle}$ \\
$A_{1}$ & 0,51 & 0,49 & 0,65 \\
$A_{2}$ & 0,68 & 0,43 & 0,53 \\
$A_{3}$ & 0,60 & 0,59 & 0,35 \\
$A^{*}$ & 0,68 & 0,59 & 0,65
\end{tabular}

The distances $\triangle Q S_{i}$ from the ideal alternative $A^{*}$ are calculated according to steps 6 and 7 : $\Delta Q S_{1}=0,1162, \Delta Q S_{2}=0,0722, \Delta Q S_{1}=0,1048$.

In accordance with step 8 alternative indicators are ordered by distance from the ideal alternative:

$$
A_{2} \succ A_{3} \succ A_{1}
$$

The result is the ordering $R=\left\{r_{i}\right\}$ of many alternatives $A$ to information systems, taking into account the uncertainty of the implementation time. The most preferable (close to the ideal) computing system will be the most suitable for improving the technological process while modernizing the observation network of the geodynamic monitoring system.

\section{CONCLUSION}

The paper considers an approach to solving the multi-criteria ranking problem of a complex technical system of geodynamic monitoring in the presence of the uncertainty factor of the alternative systems characteristics, taking into account the factors of implementation time. The problem is characterized by the fact that the scientific and technical solution and its effect depends on the applied organizational and technical decisions, taking into account the modernization time. It is proposed to consider the alternatives preference with counting of uncertainty factors of implementation time. Ranking is realized by comparing the trees of functional characteristics taking into account the additional time factor. The proposed method may find applications in problems of ranking alternatives with uncertain implementation time, modernization of information and communication environments, and network systems of geodynamic monitoring.

\section{ACKNOWLEDGEMENTS}

The work was carried out as part of a research project supported by the Ministry of Science and Higher Education of Russia No. 5.3606.2017/4.6 Точно указывать 2017 год?

\section{REFERENCES}

[1] V. N. Volkova and V. N. Kozlov, "System analysis and decision-making: dictionary-reference: Textbook for high schools", Moscow: Higher School, 616 p, 2004.

[2] Yu. V. Vedernikov and V. V. Safonov, "Multi-criteria ranking method of complex systems under different types of uncertainty of initial data", Information-control systems, No. 3, pp. 32-38, 2008.

[3] E. A. Akchurin and S. Rodionov, "Evaluation method of quality of communication services given by providers of fixed communication", Infocommunication technologies, Vol. 8, No 1, pp. 79-82, 2010.

[4] F. Carvalho de Gouveia and T. Magadanz, "Quality of service in telecommunication network", Telecommunication Systems and Technologies, Vol. 2, 21 p, 2008.

[5] S. Wallin and V. Leijon, "Multi-Purpose Models for QoS monitoring", 21st Int. Conference on Advanced Information Networking and Applications Workshops, IEEE Computer Society, pp. 900-905, 2007.

[6] R. Moradi Merni, "Plasma and its Application in Magneto-hydro-dynamical Generators", UCT Journal of Research in Science, Engineering and Technology, 4(4), 22-24, 2016.

[7] K. Malathi, et al., "Preterm birth prognostic prediction using Cross domain data fusion", International Journal of Communication and Computer Technologies, 7 (1), 10-13.

[8] W. Jörgen, "Weibull Discounted-Value Representations of Temporal Preferences", Mathematics of Operations Research, Vol. 10, No. 2, pp. 244-250, 1985.

[9] A. Gerber and K. Rohde, "Weighted Temporal Utility", Tinbergen Insti-tute Discussion Papers 13-167/1, Tinbergen Institute, September 26, 29 p, 2013. 
[10] M. Dshemuchadse, et al., "How Decisions Emerge: Action Dynamics in Intertemporal Decision Making", Journal of Exper-imental Psychology: General, Vol. 142, No. 1, pp. 93-100, 2013.

[11] G. Zauberman, et al., "Discounting Time and Time Discounting: Subjective Time Perception and Intertemporal Preferences", Journal of Marketing Research., Vol. 46, No. 4, pp. 543-556, 2009.

[12] S. Frederick, et al., "Time Discounting and Time Preference: A Critical Review", Journal of Economic Literature, Vol. 40, No. 2, pp. 351-401, 2002./12

[13] G. Gigliotti and B. Sopher, "Analysis of intertemporal choice: a new framework and experimental results", Theory and Decision, Vol. 55, pp. 209-233, 2004.

[14] S. I. Mishin, "Intertemporal preferences in decision-making: experience of experimental research in Russia", Economic journal of HSE, No. 3, pp. 404-426, 2012.

[15] N. H. KUMAR, et al., "A review on Adverse drug reactions monitoring and reporting", International Journal of Pharmacy Research \& Technology, 9 (2), 12-15.

[16] J. Pillai, et al., "A Conceptual Approach to Temporal Weighted Item set Utility Mining", International Journal of Computer Applications, Volume 1, No. 28, pp. 55-60, 2010.

[17] I. V. Loginov, "Planning of request processing in a homogeneous computer network of ACSP on the basis of utility functions", Bulletin of the Ryazan state radio engineering University, No. 2 (issue 32), pp. 105-109, 2010.

[18] A. G. Ivanov and V. A. Kukushkin, "Dynamics of consumer behavior of the subject", Bulletin of Nizhny Novgorod University named after N.I. Lobachevsky, No. 6, pp. 155-163, 2010.

[19] V. V. Zubarev, "Problem of choosing the optimal portfolio of interdependent projects with time constraints", Bulletin of the Voronezh state technical University, Vol. 7, No. 5, pp. 201-203, 2011.

[20] A. Yu. Egorov and S. V. Lisana, "Mechanisms of management of a portfolio of innovative projects in the modern enterprise", Transport case of Russia, No. 6, pp. 42-44, 2011.

[21] V. R. Smirnova, "Improvement of project portfolio management taking into account risk factors", Corporate governance and innovative development of the North: Bulletin of the Research center of corporate law, management and venture investment of Syktyvkar state University, No. 1, pp. 138-148, 2011.

[22] Fa. Tahriri, et al., "A review of Supplier Selection Methods in Manufacturing Industries", Suranaree J. Sci. Technol, Vol. 15, No. 3, Pp. 201-208, 2008.

[23] V. M. Molokanova, "Portfolios management of the organization development on the basis of fuzzy inference systems", Technical Sciences - from theory to practice, No. 28, pp. 41-48, 2013.

[24] Ya. Ti Lin, et al., "A Novel Hybrid MCDM Approach for Outsourcing Vendor Selection: A Case Study for a Semiconductor company in Taiwan", Expert System with Applications, Volume 37, Issue 7, pp. 4796-4804, 2010.

[25] S. Koul and R. Verma, "Dynamic Vendor Selection based on Fuzzy AHP Approach", Journal of Manufacturing Technology Management, Volume 22 (8), 9, pp. 963-971, 2011.

[26] B. S.Leszczynski and Yu. A. Konkin, "Supplier selection in the context of heterogeneous data using methods of fuzzy set theory", Vestnik of Tomsk state University, Economy, No. 2, pp. 44-51, 2008.

[27] C.Y. Maggie, et al., "An Application of the AHP in Vendor Selection of a Telecommunication System", Omega, No. 29, pp. 171-182, 2001.

[28] A. A. Kuzkin, Evaluation of efficiency and effectiveness of IT-processes using hybrid neuro-fuzzy networks, Internet journal of Science, No 1 (20), P. 67, 2014.

[29] A. B. Petrovskiy and G. V. Roizenson, "Multicriteria selection to reduce the dimensionality of the feature space: multi-stage technology PAKS", Artificial intelligence and decision-making, No. 4, pp. 88-103, 2012.

[30] A. B. Petrovsky, "Multi-criteria group decision making with different preference", Scientific statement of BSU, No 15(70), pp. 151-161, 2009.

[31] S.P Loke, et al., "Service Quality and Customer Satisfaction in a Telecommunication Service Provider", International Conference on Financial Management and Economics IPEDR, vol.11, IACSIT Press, Singapore, pp. 24-30, 2011.

[32] S.Y Hosseini, et al., "Providing a Multidimensional Measurement Model for Assessing Mobile Telecommunication Service Quality (MS-Qual) ", Iranian Journal of Management Studies (IJMS), Vol.6, No.2, pp: 7-29, 2013

[33] R. Melo, et al., "Sensitivity analysis techniques applied in cloud computing environments", In 2017 12th Iberian Conference on Information Systems and Technologies (CISTI) (pp. 1-7). IEEE, 2017.

[34] R. Kugyte and S. Laimona, "A Standardized Model of Service Provider Selection Criteria for Different Service Types: a Consumer-oriented Approach", Engineering Economics, No. 3 (43), pp. 56-63, 2005.

[35] S. S. Chaudhry, et al., "Vendor Selection Problem: New Formulation and Solution Approach", IADS International Conference Applied Computing, pp. 437-441, 2006.

[36] M. Sensoy and P. Yolum, "A Context-Aware Approach For Service Selection Using Ontologies", AAMAS, May, 812. Hakodate, Hokkaido, Japan, pp. 931-931, 2006.

[37] J. J. Duran and C. A. Iglesias, "A Pattern Approach to Modeling the Provider Selection Problem", ICAART, Proceedings of the International Conference on Agents and Artificial Intelligence, Vol. 2, Valencia, Spain, January 22-24, 8 p, 2010.

[38] T. K. Kravchenko, "Requirements management in the implementation of IT projects", Business Informatics, No 3 (25), pp. 63-71, 2013. 